\title{
The Influence of Communication Leadership Qualities on Effective Crisis Preparedness Strategy Implementation: Insights from a Global Study
}

Original scientific paper _ DOI 10.22522/cmr20170118 _ received on 1 April 2017 UDK 005.334:316.77

\section{Yan Jin}

Grady College of Journalism and Mass Communication, University of Georgia, U.S.A. Email: yanjin@uga.edu (corresponding author)

\section{Juan Meng}

Grady College of Journalism and Mass Communication, University of Georgia, U.S.A. Email: jmeng@uga.edu

\section{Bruce K. Berger}

College of Communication \& Information Sciences, University of Alabama, U.S.A. Email: berger@apr.ua.edu

\section{Abstract}

Based on an international online survey of communication management leaders in multiple countries, this study analyzed the responses from a total of 532 leaders who indicated crisis preparedness as a top issue for their organizations. Our results indicate: 1) Communication leaders in North America, Europe and a combination of Asia, Middle East and South America differed significantly in their implementation of crisis preparedness strategies; and 2) Different communication leadership qualities jointly predicted communication leaders' implementation of each of the crisis preparedness strategies, respectively. Our findings provide important implications for global crisis leadership theory development. Research insights from this study also shed light on the importance for international organizations to integrate communication leadership qualities with crisis preparedness strategy development and implementation.

Keywords: communication leadership, crisis leadership, crisis communication, crisis preparedness, leadership quality, global communication 


\section{Introduction}

The role of leadership in organization crises has been studied in strategic crisis management literature for three decades, which has primarily focused on how leaders have responded during a crisis situation, both proactively and reactively (e.g., Burnett, 1998; Guth, 1995; Hwang, Cameron, 2008; Johansson, Miller, Hamrin, 2014; Lucero, Kwang, Pang, 2009; Yusko, Goldstein, 1997). Such research has significantly contributed to our knowledge in leadership styles and crisis responses. However, researchers (e.g., Seegar, Ulmer, 2003; Ulmer, 2001, 2012) address there is a need to recognize the critical role of thought leadership in crisis communication. More importantly, Ulmer (2012) further advocates that identifying key communication values and attributes associated with thought leadership will definitely help organizational leaders "build their crisis communication skills" (p. 531).

Despite considerable attention and debate given to the importance of executive leadership (e.g., CEO and/or the top management team) in building supportive institutional working context when crises occurred (e.g., Porter, Nohria, 2010), there is insufficient empirical research to look specifically at the role of communication leadership (e.g., top leader in the communication unit of an organization) in managing crisis situations (i.e., How and to what extent communication leadership would contribute to effective crisis management? Are there any unique sets of communication leadership skills that would work effectively in a crisis situation?) (e.g., Berger, Meng, 2014). Therefore, this research is motivated by the desire to investigate how and to what extent communication leadership can affect responsive strategies in crisis management. More importantly, by exploring responsive communication strategies that would work more effectively when certain communication leadership skill sets were applied, our research attempts to alleviate some gaps in the existing literature, as well as further advances in the research on communication leadership and crisis management.

To achieve such research objectives, we reviewed recent research on crisis management and leadership in public relations and communication management. Significant findings relevant to communication leadership were highlighted in our review to address why such specific research on crisis management and communication leadership is needed. By applying Meng and Berger's (2013) Integrated Model of Excellence Leadership in Communication Management, we looked into an international online survey that focused on public relations 
leadership and crisis management. The international survey itself was carried out in multiple countries and regions and recruited more than 4,500 complete responses from communication professionals globally. Being inspired by the scope of this international survey, we paid close attention to a number of selected countries and regions, including North America, Europe and a combination of Asia, Middle East and South America, to look into the role of communication leadership in fostering effective crisis preparation. By using such a rich data set, we were able to explore the effects of different sets of communication leadership skills on crisis preparedness and management, from communication management leaders' perspective. Perhaps most importantly, these findings will be valuable for academics and practitioners as they navigate today's rapidly changing marketplace environment, providing insight for successful strategy implementation in crisis preparedness and management.

\section{Literature Review}

\subsection{Communication Leadership and Its Contribution to Effective Communication Management}

In the past ten years the topic of communication leadership has received significant attention from scholars in public relations and strategic communication. As advocated by the Plank Center for Leadership in Public Relations at the University of Alabama, a plethora of research projects have investigated communication leadership, from its definition, dimensions, to applications (Berger, Meng, 2010). Recently, research on communication leadership and its impact on effective communication management has focused on diverse aspects, with its roots in excellence theory in public relations, crisis communication research, managerial leadership research, and organizational communication studies. Recent research has focused on how communication professionals could apply different aspects/streams of contemporary leadership skills and behaviors (i.e., strategic decision making, ethical leadership, emotional leadership, and transformational leadership) to improve the effectiveness and organizationwide influence of communication practice (e.g. Aldoory, Toth, 2004; Choi, Choi, 2009;

Gregory, Willis, 2013; Jin, 2010; Lee, Cheng, 2011; Meng, 2014; Meng, Berger, 2013; Werder, Holtzhausen, 2011). 
Based on the wide variety of leadership research that has been carried out in public relations and communication management, Meng and Berger (2013) proposed a definition to address leadership in public relations as "a dynamic process that encompasses a complex mix of individual skills and personal attributes, values, and behaviors that consistently produce ethical and effective communication practice" (p. 143). More importantly, Meng and Berger (2013) called for attention to the multidimensional nature of communication leadership by identifying six unique but interrelated dimensions to fully explain the effectiveness of leadership practice in public relations and communication management. The six dimensions of public relations leadership include self-dynamics, team collaboration, ethical orientation, relationship building, strategic decision-making capability, and communication knowledge management (see Meng, Berger, 2013, pp. 143-150). Their continued research on public relations leadership further tested and expanded the applications and discussion of leadership dimensions in effective communication management (e.g., Berger, Meng, 2014; Meng, 2014).

Both communication professionals and organizational leaders have recognized the importance of applying appropriate leadership skills and styles in various situations to achieve both communication and organizational objectives. Such research has investigated critical concepts related to communication leadership, such as managerial role enactment (e.g., Dozier, Broom, 1995), gender role (e.g., Aldoory, Toth, 2004), innovation-related leadership communication (e.g., Zerfass, Huck, 2007), characteristics of leadership in developing and managing ethics in communication practice (e.g., Lee, Cheng, 2011), effective behavioral factors (e.g., Choi, Choi, 2009), individual traits (e.g., Meng, Berger, Heyman, 2011; Meng, et al., 2012), and dimensions of excellent public relations leadership in communication management (e.g., Meng, Berger, 2013), only a few studies have discussed the role of different leadership styles in solving decision-making conflicts in communication management (e.g., Hwang, Cameron, 2008; Jin, 2010; Shin, Heath, Lee, 2011).

For example, Hwang and Cameron (2008) found that perceived leadership style largely influences public's expectations on organizations' responses when a crisis happens. Jin (2010) found that although transformational leadership is preferred, communication leaders' skills on emotional management such as empathy also play an essential role in solving decisionmaking conflicts in a crisis. Similarly, Lee and Cheng (2011) also identified that public relations executives' personal ethics, interpersonal communication skills, and the ability 
to articulate ethical standards are salient characteristics in transferring ethical leadership into effective strategies in managing crises. Werder and Holtzhausen (2011) also confirmed that the leadership role enactment and leaders' decision-making behavior are significant predictors for organizational structural design. However, other issues, such as applying effective communication leadership skills in crisis preparedness, as well as responsive strategies to be used along with communication leadership skills, have not been fully explored, especially from an international setting when communication professionals are all facing the challenges of effective crisis preparedness and management.

\subsection{Crisis Leadership and Organizational Crisis Issue Preparedness}

Similarly, researchers have advocated for the importance of leadership in crisis management (Yusko, Goldstein, 1997). Research suggests the importance of establishing a relationship between organizational crisis experience and the placement of communication management function, which can impact how organizations handle significant financial, social, and ethical challenges in crises (Guth, 1995). Ulmer (2012) also stated that "improving crisis preparation for organizations should be a high priority" (p. 534) in crisis communication theory development. Seeger and Ulmer (2003) further advocated for the importance of "candid, ethical communication, and conversations with employees about values and ethical issues" (p. 62) in the leadership communication process.

Ulmer (2001) posited that leadership communication prior to a crisis can impact on post-crisis communication. According to Ulmer (2001), established stakeholder relationships are critical to effective crisis management, because "stakeholders have a vested interest in the success of the organization and may represent a network of support during crises" (p. 594). Lucero, Kwang and Pang (2009) studied crisis leadership with a focus on when the CEO should step up in an organizational crisis situation. Oliveira and Murphy (2009) analyzed CEO speeches during crises in order to examine the role of a leader as the face of a crisis.

Burnett (1998) advocated for a strategic approach to managing crises, which poses unique and very often unfamiliar challenges to communication managers. To explain such strategic 
approach, Burnett (1998) also identified three components in the crisis management model (p.485): (1) identification (goal formulations and environmental analyses), (2) confrontation (strategy formulation and strategy evaluation), and (3) reconfiguration (strategy implementation and strategic control). McConnell and Drennan (2006) argued that planning for crisis requires integration and synergy across organizational networks as well as active preparation through organizational training and readiness, in order to combat against uncertainty and disorder of crises.

In exploring the extent to which organizations engaged in crisis preparations, Lee, Woeste and Heath (2007) reported that organizations are better prepared for crisis handling by having a crisis plan and a crisis management team in place. Most recently, Ulmer (2012) pointed out the gap in crisis leadership research, that is, the emphasis on organizational values that have a profound impact on crisis communication. Ulmer (2012) argued that "leaders who value honest, open, and regular communication with publics are more likely to communicate in similar ways during the crisis (Ulmer, 2001)” (p. 531). Thus, Ulmer (2012) suggests organizational leaders should develop over time a list of key communication values in order to build crisis communication skills.

Therefore, it is important for organizations to have a crisis plan, maintain a crisis team, formulate comprehensive training programs, and engage in such training frequently. However, limited research has been done in the area in linking the functions of communication leadership with effective crisis preparation. To minimize the knowledge gap and contribute to the large body of leadership, as well as crisis communication research, this study extends Meng and Berger's (2013) previous research on communication leadership by developing a close focus on the role of six dimensions (i.e., self-dynamics, team collaboration, ethical orientation, relationship building, strategic decision-making, and communication knowledge management) of communication leadership in crisis preparation and management and, more significantly, in a global setting. Therefore, we proposed the following research questions to guide our study:

RQ1: How do surveyed communication leaders in North America, Europe, and a combination of Asia, Middle East and South America differ in their implementation of crisis preparedness strategies? 
RQ2: How do the surveyed communication leaders evaluate their implementation of crisis preparedness strategies differently?

RQ3: How do different communication leadership qualities together predict the surveyed communication leaders' implementation of crisis preparedness strategies, after partialing out demographics?

\section{Method}

\subsection{An Overview of the Global Online Survey}

The analyses and results reported in this study come from an international online survey about issues management, leadership performance, and leadership development in public relations and communication management (Berger, Meng, 2014). The survey was carried out in 23 countries and regions in the years of 2011-2013 as a funded global research project on public relations leadership by the Plank Center for Leadership in Public Relations (Berger, Meng, 2014). The 23 surveyed countries/regions were selected purposively not only to provide variations in geography, history, economic development, demographics, and sociocultural characteristics (see House et al., 2004), but more importantly to represent a suitable context for investigating different levels of development in the communication profession in various countries and regions. Although it is impossible to include all societies or cultures, the countries and regions investigated in this global project represent some major geographical regions in the world (i.e., Confucian Asia, Southern Asia, Eastern and Western Europe, North America, and Latin America) by using the cultural clusters developed by House, Hanges, Javidan, Dorfman and Gupta (2004). Such established cultural clusters helped us validate that surveyed geographical regions reflect diverse societal cultures, powerful economies, and varying stages of development of the communication profession.

The main purpose of this global project is to explore how dynamic changes, including globalization, the rise of social media, and empowered stakeholders have affected communication professionals' responsive strategies and how they have applied leadership skills to the management of such concerns. However, we have chosen to closely focus on the subset of responses, which include surveyed communication leaders $(\mathrm{N}=532)$ who indicated "Being 
prepared to deal effectively with crises that may arise" as the most important issue for communication leaders globally. We have relied on their responses to have a close look at the intertwined functions of crisis leadership and communication leadership in crisis preparedness and management.

\subsection{Instrumentation}

The survey items relevant to the current study consisted of questions measuring two sets of key variables, communication leadership qualities and crisis preparedness strategies, using 7-point Likert-type scales. Demographic and organizational characteristic questions were also asked.

First, survey respondents were asked to indicate their degrees of agreement with each of the seven communication leadership qualities (Meng, Berger, 2013; Meng et al., 2012) in terms of their importance in helping communication leaders deal successfully with effective crisis preparedness issue (" 1 = A little bit" to " 7 = A great deal”): 1 ) Communication Knowledge Management: "Processing communication knowledge to develop appropriate strategies, plans and messages"; 2) Strategic decision-making capability: "Participating in the organization's strategic decision-making regarding the issue [effective crisis preparedness]"; 3) Ethical orientation: "Processing a strong ethical orientation and set of values to guide actions"; 4) Team collaboration: "Having the ability to develop coalitions in and outside the organization to deal with the issue [effective crisis preparedness]"; 5): Self dynamics: "Providing a compelling vision for how communication can help the organization"; 6) Relationship building: "Having the ability to develop coalitions in and outside the organization to deal with the issue [effective crisis preparedness]"; and 7) Organizational support of 2-way communication and shared power: "Working in an organization that supports 2-way communication and shared power".

Second, survey respondents were asked to indicate to what extent their communication teams or units are implementing each of the five strategies in order to help their organizations more effectively prepare for rising crises (Zerfass et al., 2010) (" $1=$ A little bit" to " $7=\mathrm{A}$ great deal”): 1) “Developing effective crisis communication plans for action”; 2) “Using issue scanning and monitoring technologies to identify and track potential problems"; 3) "Providing employees with training for crisis management procedures"; 4) "Educating stakeholders about 
emergency communications and related response systems"; and 5) "Implementing effective issues management program to reduce the risk of crises”.

\subsection{Data Analysis}

MANOVA was used to examine how the surveyed communication leaders' implementation of crisis preparedness strategies differed by their regions (i.e. North America, Europe, and other surveyed countries). One-sample t-test was used to examine how surveyed communication leaders evaluated their implementation of crisis preparedness strategies differently. Hierarchical regressions were used to examine how the seven communication leadership qualities together predict the surveyed communication leaders' implementation of each of the five crisis preparedness strategies, respectively, after controlling for demographics (i.e. gender, age, and years of professional experience in communication management).

\section{Results}

\subsection{Respondent Characteristics}

Among the 532 surveyed communication leaders who regarded crisis preparedness as a top issue for communication management, 136 were from North America, 251 were from Europe, and 145 were from a combination of Asia, Middle East and South America. Among these leaders, $52 \%$ were male and $48 \%$ were female. The majority of them were in the 36-45 (30\%) and 46-55 (30\%) age groups, followed by the age groups of 25-35 (21\%), 56-65 (15\%), less than 25 (3\%) and more than 65 (2\%). The highest education received by most of the respondents was a master's degree (45\%), followed by a bachelor's degree (37\%), a doctoral degree (10\%), other (5\%), and high school degree or equivalent (3\%). The majority has more than 20 years of experience in communication management (29\%), followed by 11-15 years (25\%), 5-10 years (20\%), $16-20$ years (14\%), and less than 5 years (13\%).

In hierarchical regression analyses, age was re-coded to " $1=<36$ " (24\%) and " $0=36$ or above" (76\%), and years of professional experience in communication management was re-coded to “ 1 = less than 11 years" (33\%) and " $0=11$ years or more" (68\%). 
Descriptive statistics of surveyed communication leaders' implementation of crisis preparedness strategies by region are listed in Table 1. Descriptive statistics of crisis preparedness strategy implementation and communication leadership qualities across individual leaders are listed in Table 2.

\subsection{Differences in Crisis Preparedness Strategy Implementation by Region and Across Individuals}

RQ1 asked how the surveyed communication leaders in North America, Europe, and a combination of Asia, Middle East and South America might differ in their implementation of crisis preparedness strategies. MANOVA was conducted to examine whether and how communication leaders in North America, Europe and a combination of Asia, Middle East and South America differed in their implementation of each of the five crisis preparedness strategies, respectively. Significant findings (see Table 1) revealed:

First, communication leaders in both North America $(M=6.01, S E=.12)$ and a combination of Asia, Middle East and South America $(M=5.86, S E=.11)$ implemented more the strategy of "Developing effective crisis communication plans for action" than communication leaders in Europe $(M=5.37, S E=.09)\left(\mathrm{F}[2,529]=11.90, \mathrm{p}<.001\right.$, par. $\left.\eta^{2}=.04\right)$.

Second, communication leaders in North America $(M=4.95, S E=.13)$ and Europe $(M=4.76$, $S E=.10)$ implemented less the strategy of "Using issue scanning and monitoring technologies to identify and track potential problems" than communication leaders in a combination of Asia, Middle East and South America $(M=5.66, S E=.13)\left(\mathrm{F}[2,529]=15.98, \mathrm{p}<.001\right.$, par. $\left.\eta^{2}=.06\right)$.

Third, communication leaders in Europe $(M=4.62, S E=.10)$ implemented less the strategy of "Providing employees with training for crisis management procedures" than those in a combination of Asia, Middle East and South America (excluding North America) $(M=5.21, S E=.13)$ (F $[2,529]=6.11, \mathrm{p}<.001$, par. $\left.\eta^{2}=.02\right)$. There was no significant difference between leaders in North America and those in Europe or a combination of Asia, Middle East and South America.

Fourth, communication leaders in a combination of Asia, Middle East and South America ( $M$ $=5.46, S E=.13)$ implemented more the strategy of "Educating stakeholders about emergency 
communications and related response systems" than North America $(M=5.01, S E=.13)$, while communication leaders in Europe $(M=4.59, S E=.10)$ implemented such a strategy the least $\left(\mathrm{F}[2,529]=15.25, \mathrm{p}<.001\right.$, par. $\left.\eta^{2}=.06\right)$.

Fifth, communication leaders in both North America $(M=5.55, S E=.14)$ and a combination of Asia, Middle East and South America $(M=5.70, S E=.14)$ implemented more the strategy of "Implementing effective issues management program to reduce the risk of crises" than communication leaders in Europe $(M=4.54, S E=.10)\left(\mathrm{F}[2,529]=29.60, \mathrm{p}<.001\right.$, par. $\left.\eta^{2}=.10\right)$.

Table 1. Pairwise comparisons of region mean scores on crisis preparedness strategies

\begin{tabular}{|c|c|c|c|c|}
\hline $\begin{array}{l}\text { Implementation of Crisis } \\
\text { Preparedness Strategies }\end{array}$ & $\begin{array}{l}\text { North } \\
\text { America }\end{array}$ & Europe & $\begin{array}{l}\text { Asia, Middle } \\
\text { East and } \\
\text { South } \\
\text { America }\end{array}$ & $\begin{array}{c}\text { df } \\
\text { F }[2,529]\end{array}$ \\
\hline $\begin{array}{l}\text { Developing effective crisis } \\
\text { communication plans for action }\end{array}$ & $6.01(.12)$ & $5.37(.09)$ & $5.86(.11)$ & $11.90^{* * n+a x}$ \\
\hline $\begin{array}{l}\text { Using issue scanning and } \\
\text { monitoring technologies to } \\
\text { identify and track potential } \\
\text { problems }\end{array}$ & $4.95(.13)$ & $4.76(.10)$ & $5.66(.13)$ & $15.98^{* * * * *}$ \\
\hline $\begin{array}{l}\text { Providing employees with } \\
\text { training for crisis management } \\
\text { procedures }\end{array}$ & $4.84(.14)$ & $4.62(.10)$ & $5.21(.13)$ & $6.11^{* * *}$ \\
\hline $\begin{array}{l}\text { Educating stakeholders about } \\
\text { emergency communications and } \\
\text { related response systems }\end{array}$ & $5.01(.13)$ & $4.59(.10)$ & $5.46(.13)$ & $15.25^{\text {swak }}$ \\
\hline $\begin{array}{l}\text { Implementing effective issues } \\
\text { management program to reduce } \\
\text { the risk of crises }\end{array}$ & $5.55(.14)$ & $4.54(.10)$ & $5.70(.14)$ & $29.60^{* * * * *}$ \\
\hline
\end{tabular}

Note. Cell entries are estimated marginal means. Pairwise planned comparisons are adjusted for Bonferroni multiple comparisons. Standard errors are in parentheses. Significance for the multivariate $\mathrm{F}$ is based on estimates of the marginal means for the Wilk's Lamda statistic. $* \mathrm{p}<.05 ; * * \mathrm{*}<.01 ;{ }^{* * * * *}: \mathrm{p}<.001$.

RQ2 asked how surveyed communication leaders might evaluate their implementation of crisis preparedness strategies differently. Comparing individual leaders across the survey sample, significant differences were detected among their evaluations of different crisis preparedness strategies (see Table 2). Specifically, "Developing effective crisis communication 
plans for action" ( $M=5.67, S D=1.39$ ) was implemented the most by surveyed leaders ( $\mathrm{t}[531]$ $=94.26, \mathrm{p}<.001)$, followed by "Implementing effective issues management program to reduce the risk of crises" $(M=5.11, S D=1.72)(\mathrm{t}[531]=68.74, \mathrm{p}<.001)$ and “Using issue scanning and monitoring technologies to identify and track potential problems" $(M=5.05, S D=1.58)(\mathrm{t}[531]=$ $73.79, \mathrm{p}<.001)$. The relatively less implemented crisis preparedness strategies were "Educating stakeholders about emergency communications and related response systems" ( $M=4.93, S D=$ 1.57) $(\mathrm{t}[531]=72.33, \mathrm{p}<.001)$ and "Providing employees with training for crisis management procedures” $(M=4.84, S D=1.62)(\mathrm{t}[531]=68.83, \mathrm{p}<.001)$.

Table 2. Descriptive statistics and one-sample $t$ tests on leaders' implementation of crisis preparedness strategies and communication leadership qualities

Implementation of Crisis Preparedness Strategies

Developing effective crisis communication plans for action

Using issue scanning and monitoring technologies to identify and track potential problems

Providing employees with training for crisis management procedures

Educating stakeholders about emergency communications and related response systems

Implementing effective issues management program to reduce the risk of crises

\section{Communication Leadership Qualities}

Communication Knowledge Management

Strategic Decision-Making Capability

Ethical Orientation

Team Collaboration

Self Dynamics

Relationship Building

Organizational Support of 2-Way Communication and Shared Power
Mean (SD)

$\mathrm{t}$-value

[df $=531]$

$94.26^{* * * * *}$

5.67 (1.39)

$73.79^{* * * *}$

$5.05(1.58)$

4.84 (1.62)

$68.83^{\text {*****x+1}}$

4.93 (1.57)

$72.33^{* * * x}$

$5.11(1.72)$

$68.74^{* * * * x}$ t-value

[df $=531]$

$*$ p $<.05 ; * *$ p $<.01 ; * * * *$ p $<.001$.

$6.30(.93) \quad 156.14^{* * * *}$

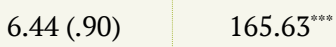

$5.84(1.23) \quad 109.59^{* * * *}$

$5.99(1.08) \quad 128.06^{\text {wakn }}$

$5.87(1.21) \quad 111.68^{* * m+k}$

$5.83(1.24) \quad 108.89^{* * * *}$

$5.45(1.46) \quad 86.33^{* * n+\infty}$ 


\subsection{Communication Leadership Predictors of Crisis Preparedness Strategy Implementation}

RQ3 asked how different communication leadership qualities together might predict surveyed communication leaders' implementation of crisis preparedness strategies, after partialing out demographics. Hierarchical regression models, partialing out demographics (i.e., gender, age, and years of professional experience in communication management) previously found to influence communication leadership outcomes (e.g., Jin, 2010), were used to examine the association between the perceived importance of the seven communication leadership qualities, as predictors, and the extent of implementation of the five strategies for effective crisis preparedness, as outcome variables, respectively.

In terms of the overall influences of gender, age, and years of professional experience in communication management, we found (see Table 2): 1) Across all regression models, gender of a communication leader was not a significant predictor of crisis preparedness strategy implementation; 2) The implementation of "Using issue scanning and monitoring technologies to identify and track potential problems" and "Implementing effective issues management program to reduce the risk of crises" was significantly influenced by age: Younger leaders (younger than 36) implemented more of these two crisis preparedness strategies than older leaders did; and 3) Leaders with 11 or more years of professional experience in communication management implemented more crisis preparedness strategies across the board than leaders with less than 11 years of experience did.

Key findings (see Table 3), regarding leadership quality predictors for crisis preparedness strategy implementation, after partialing out demographics, include:

First, the significant communication leadership quality predictors $(\mathrm{F}[10,521]=7.29, p<.001$, adjusted R square $=.11$ ) for "Developing effective crisis communication plans for action" are: 1 ) Communication knowledge management:"Processing communication knowledge to develop appropriate strategies, plans and messages" (beta $=.13, \mathrm{t}=2.63, p<.01$ ); 2 ) Strategic decisionmaking capability: "Participating the organization's strategic decision-making regarding effective crisis preparedness" (beta $=.10, \mathrm{t}=2.11, p<.05$ ); and 3) Team collaboration: "Having the ability to develop coalitions in and outside the organization to develop effective crisis preparedness" (beta $=.12, \mathrm{t}=2.27, p<.05$ ). 
Second, the only significant communication leadership predictor $(\mathrm{F}[10,521]=6.36, p<.001$, adjusted R square $=.09$ ) for "Using issue scanning and monitoring technologies to identify and track potential problems" is Team collaboration: "Having the ability to develop coalitions in and outside the organization to develop effective crisis preparedness" (beta $=.14, \mathrm{t}=2.41, p<.05$ ).

Third, the significant communication leadership quality predictors $(\mathrm{F}[10,521]=7.11, p<$ .00 ', adjusted R square $=.10$ ) for "Providing employees with training for crisis management procedures" are: 1) Communication knowledge management: "Processing communication knowledge to develop appropriate strategies, plans and messages" (beta $=.12, \mathrm{t}=2.34, p$ $<.05)$; 2) Team collaboration: "Having the ability to develop coalitions in and outside the organization to develop effective crisis preparedness" (beta $=.12, \mathrm{t}=2.14, p<.05$ ); and 3) Self dynamics: "Providing a compelling vision for how communication can help the organization" (beta $=.12, \mathrm{t}=2.29, p<.05$ ).

Fourth, the only significant communication leadership predictor $(\mathrm{F}[10,521]=7.12, p<.001$, adjusted R square $=.10$ ) for "Educating stakeholders about emergency communications and related response systems" is Organizational support of 2-way communication and shared power: "Working in an organization that supports 2-way communication and shared power" (beta $=.12, \mathrm{t}=2.29, p<.05$ ).

Fifth, the significant communication leadership quality predictors $(\mathrm{F}[10,521]=10.03, p<.001$, adjusted $\mathrm{R}$ square $=.15$ ) for "Implementing effective issues management program to reduce the risk of crises" are: 1) Communication knowledge management: "Processing communication knowledge to develop appropriate strategies, plans and messages" (beta $=.13, \mathrm{t}=2.70, p<$ $.01)$; 2) Ethical orientation: "Processing a strong ethical orientation and set of values to guide actions" (beta $=.16, \mathrm{t}=2.97, p<.01$ ); and 3) Relationship building: "Having the ability to develop coalitions in and outside the organization to develop effective crisis preparedness" (beta $=.12, \mathrm{t}=2.16, p<.05)$. 
Table 3. Hierarchical regressions predicting implementation of crisis preparedness strategies

\begin{tabular}{|c|c|c|c|c|c|}
\hline Predictors & $\begin{array}{l}\text { Developing } \\
\text { effective crisis } \\
\text { communication } \\
\text { plans for } \\
\text { action }\end{array}$ & $\begin{array}{l}\text { Using issue } \\
\text { scanning and } \\
\text { monitoring } \\
\text { technologies } \\
\text { to identify and } \\
\text { track potential } \\
\text { problems }\end{array}$ & $\begin{array}{l}\text { Providing } \\
\text { employees } \\
\text { with training } \\
\text { for crisis } \\
\text { management } \\
\text { procedures }\end{array}$ & $\begin{array}{l}\text { Educating } \\
\text { stakeholders } \\
\text { about emergency } \\
\text { communications } \\
\text { and related } \\
\text { response systems }\end{array}$ & $\begin{array}{l}\text { Implementing } \\
\text { effective issues } \\
\text { management } \\
\text { program to } \\
\text { reduce the risk } \\
\text { of crises }\end{array}$ \\
\hline & Beta & Beta & Beta & Beta & Beta \\
\hline $\begin{array}{l}\text { Block } 1 \\
\text { Gender } \\
\text { Age } \\
\text { Years of } \\
\text { Experience }\end{array}$ & $\begin{array}{l}-.027 \\
.073 \\
-.175^{* *}\end{array}$ & $\begin{array}{l}-.019 \\
.212^{* * * *} \\
-.122^{*}\end{array}$ & $\begin{array}{l}-.061 \\
.038 \\
-.115^{*}\end{array}$ & $\begin{array}{l}.010 \\
.051 \\
-.136^{*}\end{array}$ & $\begin{array}{l}-.014 \\
.134^{*} \\
-.190^{* * * * *}\end{array}$ \\
\hline R-square & .022 & .028 & .015 & .012 & .024 \\
\hline $\begin{array}{l}\text { Block } 2 \\
\text { Communication } \\
\text { Knowledge } \\
\text { Management }\end{array}$ & $.129^{* * *}$ & .065 & $.115^{*}$ & .041 & $.129 * *$ \\
\hline $\begin{array}{l}\text { Strategic } \\
\text { Decision-Making } \\
\text { Capability }\end{array}$ & $.104^{*}$ & -.009 & -.038 & .008 & -.029 \\
\hline $\begin{array}{l}\text { Ethical } \\
\text { Orientation }\end{array}$ & .026 & .021 & .042 & .047 & $.155^{* *}$ \\
\hline $\begin{array}{l}\text { Team } \\
\text { Collaboration }\end{array}$ & $.122^{*}$ & .096 & $.115^{*}$ & .076 & .057 \\
\hline Self Dynamics & .026 & .079 & $.116^{*}$ & .075 & .044 \\
\hline $\begin{array}{l}\text { Relationship } \\
\text { Building }\end{array}$ & .032 & $.135^{*}$ & .069 & .105 & $.118^{*}$ \\
\hline $\begin{array}{l}\text { Organizational } \\
\text { Support of 2-Way } \\
\text { Communication } \\
\text { and Shared } \\
\text { Power }\end{array}$ & .008 & .002 & .034 & $.117^{*}$ & .046 \\
\hline R-square & .123 & .109 & .120 & .120 & .161 \\
\hline Total R-square & .145 & .137 & .135 & .133 & .185 \\
\hline R-square change & $.101^{* * * *}$ & $.081^{* * * *}$ & $.105^{* * * * *}$ & $.108^{* * * * *}$ & $.138^{* * * * *}$ \\
\hline
\end{tabular}




\section{Disculssion}

These results provide important implications for crisis leadership theory development and insights for organizations on how to integrate communication leadership qualities or personal abilities with crisis preparedness strategy development and implementation within an organization, which contributes to the daunting organizational mission of planning and preparing for crisis (McConnell, Drennan, 2006) that strives for strategic excellence (Lee, Woeste, Health, 2007).

\subsection{How Communication Leadership Qualities Influence Organizations' Implementation of Effective Crisis Preparedness Strategies}

Comparing individual leaders across the survey sample, "Developing effective crisis communication plans for action", "Implementing effective issues management program to reduce the risk of crises" and "Using issue scanning and monitoring technologies to identify and track potential problems" seem to be implemented the most by surveyed leaders. The less implemented crisis preparedness strategies seem to be "Educating stakeholders about emergency communications and related response systems" and "Providing employees with training for crisis management procedures".

Our findings further indicate that communication leaders in North America, Europe and a combination of Asia, Middle East and South America differed in their implementation of each of the five crisis preparedness strategies. On the one hand, compared to leaders in North America and other surveyed countries, European communication leaders seem to implement less "Developing effective crisis communication plans for action", "Using issue scanning and monitoring technologies to identify and track potential problems", "Providing employees with training for crisis management procedures", "Educating stakeholders about emergency communications and related response systems", and "Implementing effective issues management program to reduce the risk of crises", across the board when it comes to organizational crisis issue preparedness. On the other hand, communication leaders in North America and a combination of Asia, Middle East and South America implemented more "Developing effective crisis communication plans for action" and "Implementing effective issues management program to reduce the risk of 
crises". In addition, the surveyed countries, other than those in North America and Europe, implemented "Using issue scanning and monitoring technologies to identify and track potential problems" and "Educating stakeholders about emergency communications and related response systems" strategies the most.

The seven communication leadership qualities, together, seem to serve as effective predictors of the implementation of the five strategies for effective crisis preparedness. Specifically: 1 ) Communication knowledge management ("Processing communication knowledge to develop appropriate strategies, plans and messages") seems to predict the extent of communication leaders' implementation of "Developing effective crisis communication plans for action", "Providing employees with training for crisis management procedures", and "Implementing effective issues management program to reduce the risk of crises". 2) Strategic decision-making capability ("Participating in the organization's strategic decision-making regarding effective crisis preparedness") seems to predict the extent of communication leaders' implementation of "Developing effective crisis communication plans for action". 3) Team collaboration ("Having the ability to develop coalitions in and outside the organization to develop effective crisis preparedness") seems to predict the extent of communication leaders' implementation of "Developing effective crisis communication plans for action", "Using issue scanning and monitoring technologies to identify and track potential problems", and "Providing employees with training for crisis management procedures". 4) Self dynamics ("Providing a compelling vision for how communication can help the organization") seems to predict the extent of communication leaders' implementation of "Providing employees with training for crisis management procedures". 5) Organizational support of 2-way communication and shared power ("Working in an organization that supports 2-way communication and shared power") seems to predict the extent of communication leaders' implementation of "Educating stakeholders about emergency communications and related response systems". 6) Ethical orientation ("Processing a strong ethical orientation and set of values to guide actions") seems to predict the extent of communication leaders' implementation of "Implementing effective issues management program to reduce the risk of crises". 7) Relationship building ("Having the ability to develop coalitions in and outside the organization to develop effective crisis preparedness") seems to predict the extent of communication leaders' implementation of "Implementing effective issues management program to reduce the risk of crises". 
Influential demographics identified by our findings are communication leaders' age and years of professional experience in communication management. First, younger leaders implemented more "Using issue scanning and monitoring technologies to identify and track potential problems" and "Implementing effective issues management program to reduce the risk of crises" crisis preparedness strategies than older leaders did across region. Second, communication leaders with more years of professional experience implemented more crisis preparedness strategies across the board than leaders with fewer years of professional experience.

\subsection{Implications for Communication Management Research and Practice}

The major contribution of this study is to confirm the importance of mastering different communication leadership skills in order to be prepared for effective crisis management. Although the three regions (North America, Europe, and a combination of Asia, Middle East and South America) we analyzed in this study reported significantly different levels in crisis preparedness, our regression models confirmed that communication leadership skills need to be tailored to fit the unique expectation of crisis preparedness. Such an important finding reveals the practical implication for communication professionals when they actively seek out leadership development opportunities. It will be extremely important to develop and design tailored crisis management plans by applying appropriate leadership skill sets.

After confirming the critical relationship between crisis preparedness and communication leadership, we were also able to identify that several unique dimensions of excellent leadership in public relations and communication management were significantly important in seeking crisis preparedness strategies. The dimension of communication knowledge and management, in particular, appears to have a strong linkage with crisis preparedness as indicated by communication leaders across three regions. This finding further confirmed the uniqueness of communication management in fostering organizational effectiveness, both in routine and non-routine situations as addressed by Hwang and Cameron (2008) in their research that leadership style strongly affects public's expectations, which are direct outcomes of communication management. 
While the crisis communication literature has widely addressed the importance of applying varied crisis responses, results from this study confirmed that communication leaders must possess a range of leadership skills and capabilities and then draw from them to varying extents in managing crises effectively. Such findings echoed the multidimensional nature of leadership in public relations and communication management as Meng and Berger (2013) explained. Although practitioners surveyed in this study are located in different countries and societies, the common themes on the role of communication leadership in crisis preparedness and management were identified, along with a determined acceptance of leadership capabilities as crucial qualities in implementing crisis preparedness strategies. The results further strengthen current research results on communication leadership (e.g., Lee, Cheng, 2011; Werder, Holtzhausen, 2011) but add a unique aspect in helping us understand how the applications of certain leadership capabilities can support crisis preparedness strategies.

\subsection{Limitations and Future Research}

As we discussed earlier, our research provided solid evidence of the relationship between communication leadership and crisis preparedness from the perspective of communication management. Such evidence is stronger as we were able to look into this issue from a global perspective. The surveyed communication leaders from different regions shared their own practices in selecting different communication leadership skills when preparing for crisis responses. The results point to the importance of mastering a wide variety of communication leadership skills, but it is even more important to be able to solidify the most appropriate communication leadership skill sets when the challenges from each crisis varied. Such results can be used as the basis for further theory development when investigating crisis communication leadership.

However, we fully realize the limitations of this study. The first limitation is about the unbalanced subsets of respondents in our sample. It is fortunate for us to be able to work with a rich international online survey data set and to look into the responses from North America, Europe and a combination of Asia, Middle East and South America. However, the number of respondents who participated in this survey from each region varied significantly. Thus, future research should address such limitation by making efforts to recruit equal and 
balanced samples from each investigated country or region. Such efforts will minimize regional biases and provide a clear picture of universally applied and/or regional specific answers to crisis preparedness, as well as the application of communication leadership. Future research should also compare responses from leaders indicating crisis preparedness as an important issue with responses from those who indicate otherwise, factoring in the varied perceived value of crisis preparedness among leaders.

In addition, this study focused more on communication leadership as a resource when preparing for crisis management. It is important for future research to design comparative studies to explore the role of communication leadership in both crisis preparedness and crisis management. The choices and decisions communication leaders make in crisis prevention and crisis recovery might be dramatically different, depending on the scope and levels of impact of the crisis itself. It will be critical for practitioners to be prepared with sufficient and appropriate communication leadership skill sets to cope with various situations.

\section{Reference List}

- Aldoory, L., Toth, E. (2004). Leadership and gender in public relations: Perceived effectiveness of transformational and transactional leadership styles. Journal of Public Relations Research, 16, 157-183.

- Berger, B. K., Meng, J. (2010). Public relations practitioners and the leadership challenge. In: Heath, R. L. (Ed.), The SAGE handbook of public relations (pp. 421-434). Thousand Oaks, CA: SAGE publications.

- Berger, B. K., Meng, J. (Eds.) (2014). Public relations leaders as sensemakers: A global study of leadership in public relations and communication management. New York: Routledge.

- Burnett, J. J. (1998). A strategic approach to managing crisis. Public Relations Review, 24 (4), 475-488.

- Choi, J., Choi, Y. (2009). Behavioral dimensions of public relations leadership in organizations. Journal of Communication Management, 13, 292-309.

- Dozier, D. M., Broom, G. M. (1995). Evolution of the manager role in public relations practice. Journal of Public Relations Research, 7, 3-26.

- Gregory, A., Willis, P. (2013). Strategic public relations leadership. New York: Routledge.

- Guth, D. W. (1995). Organizational crisis experience and public relations roles. Public Relations Review, 21 (2), $123-136$.

- House, R. J., Hanges, R. J., Javidan, M., Dorfman, P., Gupta, V. (Eds.) (2004). GLOBE, cultures, leadership, and organizations: GLOBE study of 62 societies. Thousand Oak, CA: SAGE publications.

- Hwang, S., Cameron, G. T. (2008). Public's expectation about an organization's stance in crisis communication based on perceived leadership and perceived severity of threats. Public Relations Review, 34, 70-73.

- Jin, Y. (2010). Emotional leadership as a key dimension of public relations leadership: A national survey of public relations leaders. Journal of Public Relations Research, 22, 159-181.

- Johansson, C., Miller, V. D., Hamrin, S. (2014). Conceptualizing communicative leadership: A framework for analyzing and developing leaders' communication competence. Corporate Communications: An International Journal, 19 (2), $147-165$.

- Lee, J., Woeste, J. H., Heath, R. L. (2007). Getting ready for crises: Strategic excellence. Public Relations Review, 33, $334-336$. 
- Lee, S. T., Cheng, I.-H. (2010). Characteristics and dimensions of ethical leadership in public relations. Journal of Public Relations Research, 23, 46-74.

- Lucero, M., Kwang, A. T. T., Pang, A. (2009). Crisis leadership: When should the CEO step up? Corporate Communications: An International Journal, 14 (3), 234-248.

- McConnell, A., Drennan, L. (2006). Mission Impossible? Planning and preparing for crisis. Journal of Contingencies and Crisis Management, 14 (2), 59-70.

- Meng, J. (2014). Unpacking the relationship between organizational culture and excellent leadership in public relations. Journal of Communication Management, 18 (4), 363-385.

- Meng, J., Berger, B. K. (2013). An integrated model of excellent leadership in public relations: Dimensions, measurement, and validation. Journal of Public Relations Research, 25 (2), 141-167.

- Meng, J., Berger, B. K., Heyman, W. C. (2011). Measuring public relations leadership in the trait approach: A second-order factor model in the dimension of self-dynamics. Public Relations Journal, 5 (1). Retrieved from: http://www.prsa.org/ SearchResults/download/6D-050105/0/Measuring_Public_Relations_Leadership_in_the_Trait. July 15, 2017.

- Meng, J., Berger, B. K., Gower, K. K., Heyman, W. C. (2012). A test of excellent leadership in public relations: Key qualities, valuable sources, and distinctive leadership perceptions. Journal of Public Relations Research, 24 (1), 18-36.

- Oliveira, M. d. F., Murphy, P. (2009). The leader as the face of a crisis: Philip Morris' CEO’s speeches during the 1990s. Journal of Public Relations Research, 21 (4), 361-380.

- Porter, M. E., Nohria, N. (2010). What is leadership? The CEO’s role in large, complex organizations. In: Nohria, N., Khurana, R. (Eds.), Handbook of leadership theory and practice (pp. 433-473). Boston, MA: Harvard Business School Publishing.

- Seeger, M. W., Ulmer, R. R. (2003). Communication and Responsible Leadership. Management Communication Quarterly, 17 (1), 58-84.

- Shin, J. H., Heath, R. L., Lee, J. (2011). A contingency explanation of public relations practitioner leadership style: Situation and culture. Journal of Public Relations Research, 23, 167-190.

- Ulmer, R. R. (2001). Effective crisis management through established stakeholder relationships. Management Communication Quarterly, 14 (4), 590-615.

- Ulmer, R. R. (2012). Increasing the impact of thought leadership in crisis communication. Management Communication Quarterly, 26 (4), 523-542.

- Werder, K. P., Holtzhausen, D. (2009). An analysis of the influence of public relations department leadership style on public relations strategy use and effectiveness. Journal of Public Relations Research, 21, 404-427.

- Yusko, K. P., Goldstein, H. W. (1997). Selecting and developing crisis leaders using competency-based simulations. Journal of Contingencies and Crisis Management, 5 (4), 216-223.

- Zerfass, A., Huck, S. (2007). Innovation, communication, and leadership: New developments in strategic communication. International Journal of Strategic Communication, 1 (2), 107-122.

- Zerfass, A., Tench, R., Verhoeven, P., Vercic, D., Moreno, A. (2010). European Communication Monitor 2010: Status quo and challenges of public relations in Europe. Results of an empirical survey in 46 countries. Brussels, Belgium: EACD/EUPRERA, Helios Media. 


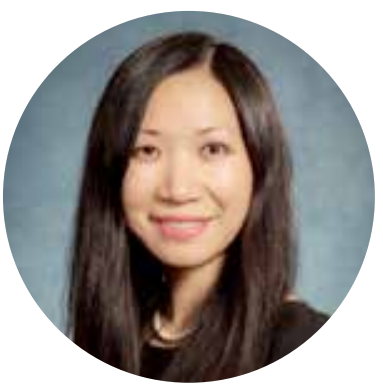

Yan Jin

Yan Jin is an associate professor of public relations and associate director of the Center for Health and Risk Communication at University of Georgia. Her research focuses on crisis communication, social media, and the role of emotions in strategic conflict management. She has authored 58 journal articles and 20 book chapters. She is the co-editor of the book, Social Media and Crisis Communication. She has presented more than 100 papers and received 14 top paper awards at national and international research conferences. She received the AEJMC's Krieghbaum Under-40 Award and is a member of the Arthur W. Page Society.

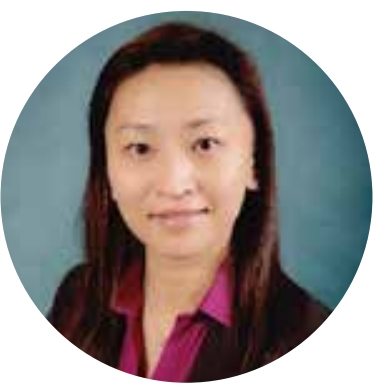

\section{Juan Meng}

Juan Meng is an associate professor of advertising and public relations at the University of Georgia. Her current research focuses on leadership in public relations, leadership development, talent management, trust in reputation management, and employee engagement. Meng has published her research in leading scholarly journals in public relations and communication management. Meng is the co-editor of the scholarly book, Public Relations Leaders as Sensemakers: A Global Study of Leadership in Public Relations and Communication Management. Meng is a research fellow with the Plank Center for Leadership in Public Relations and a member of the Page Up Society.

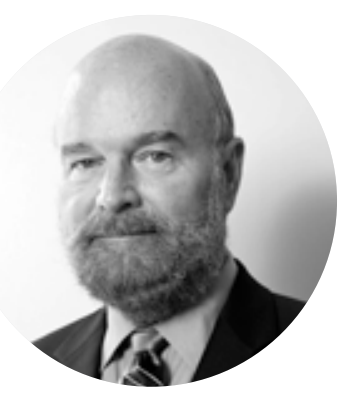

Bruce K. Berger

Bruce K. Berger is professor emeritus of advertising and public relations at the University of Alabama. He serves as research director for the Plank Center for Leadership in Public Relations Research at the University of Alabama. Previously, Berger was a public relations professional and executive for The Upjohn Company and Whirlpool Corporation for 20 years. His research focuses on communication management and leadership, employee communications and power relations inside organizations. He has authored or edited four books and more than 80 book chapters and scholarly and professional articles. 